\title{
Talking about How to Overcome Psychological Tension in the Vocal Music Performance
}

\author{
Weiwei FAN \\ Shandong Woman University
}

\begin{abstract}
The psychological tension in the vocal music performance is a common problem existing in each vocal performer and has long troubled the vocal performer. The exceeding psychological tension is harmful to vocal performers. It not only brings a series of psychological burden to vocal performer, but also directly influences the quality of song track, the status of singing and the quality of sang song of vocal performer, therefore, establish and develop excellent psychological quality is the premise for vocal performers to carry out a normal singing. This paper tries to help vocal performers overcome some psychological tension in the vocal music performance in following ways. Hope to bring some help to vocal performers.
\end{abstract}

KEYWORD: Vocal music performance; psychological tension; enhancing self-confidence and consummate skills

The psychological activity in the vocal music performance plays a positive or negative role in the songs that the vocal performer plays, and at the same time influences its quality. A good psychological phenomenon and psychological state is the basis and premise to sing vocal music works successfully. If so, we must first understand the primary cause of bad psychological phenomenon. The conclusion of anatomical physiology tells us that human nervous system is divided into two parts, that's, central nervous system and peripheral nervous system. The human brain is a central nervous system and any of the organs in the body is subject to the central nervous system, namely, being controlled by the brain. While cerebral cortex is the highest part in the central nervous system and is an organ to carry out higher nervous activity. Pavlov once pointed out "The normal activity of cerebral cortex is determined by the strength, flexibility and balance in the nervous process. If the balance is destroyed, the condition of excessive increase or decrease will exist in the process of excitation and inhibition and it will make higher nervous activity under the state of disorder". In other words, in general, the process of excitation and inhibition for the cerebral cortex is mutual equilibrium and mutual suppression. When the vocal performer sings the vocal music works, many cases not occurring at ordinary times will occur, for example, the basic skills of singing is not solid; the problem of treble is not grasped; degree of familiarity and proficiency of works are not enough; the grasping of song emotion is not adequate, and the emotion and thought could not be expressed intensively; the stage experience is not rich enough, and the lack of practicalness and experience of stage performance. All of these cause the vocal performers perform imperfectly when expressing the vocal music works on the stage. However, we shall have a comprehensive and systematic understanding for this kind of psychological tension. When singing in the face of a broad audience and judge, the vast majority of performers will inevitably generate invisible psychological pressure. This kind of psychological tension is very normal. Many experienced vocal performers are able to transform this kind of tension into moderate excitement freely. This kind of moderate excitement is necessary for vocal performers in the process of vocal music performance. Sometimes, under this kind of necessary psychological tension, it will mobilize the mind and body of the performer and even many vocal performers perform beyond their capacities. Therefore, in order to achieve the success of the performance, the moderate psychological tension is also necessary. However, this kind of psychological tension can't exist exceedingly. The excessive psychological tension sometimes could not have a good performance effect and even becomes the stumbling block of the performance. The psychological tension shall belong to psychological fear. At this time, many vocal performers will have the feeling of fear and become lack of self- 
confidence when performing, naturally, it has formed an unique excitement in the central nervous system. This kind of excitatory process is very long and strong, which has been beyond self-control of vocal performer. This is what we usually called "stage fright". "Stage fright" is an extremely abnormal phenomenon for the mentality of the people and is caused by a series of abnormal psychological and physiological process. Now, here are several suggestions for vocal performers to overcome the psychological tension in the following ways. Hope to help the vocal performers to overcome this kind of psychological tension.

\section{KEEPING STRONG SELF-CONFIDENCE, TRAINING HARD AND IMPROVING THE SINGING SKILLS}

Self-confidence is a necessary psychological quality to obtain a successful singing. Only confident enough one can get totally relaxed. The performer can play normally only under relaxed circumstance. What's more, self-confidence is the best weapon to overcome the psychological tension. However, this kind of strong self-confidence shall be based on a powerful singing skill and singing strength. The performers have no self-confidence in singing unless their singing capacity has achieved a certain level and they have chosen a proper works. Believe that as long as the performers can play at their normal level, it's natural for completing successful vocal music works. Arthur Rubinstein, the renowned American pianist said, "When I get into the pageant, I'm the king". This shows that self-confidence has played an essential role in the way to success. At the same time, the performers should participate in more performances, so as to be familiar with the stage environment, acoustic equipment, orchestral songs, audio accompaniment and stage lighting and relieve the psychological tension. Before the vocal music performance, the performers shall do more deepbreathing exercises to be relaxed, so as to make vocal organs and throat relaxed and further achieve the effect of easing the psychological tension. At the same time, the performers should learn to divert their attention from some unnecessary distractions as far as possible, stabilize their intense emotions and eliminate the tension. In addition, the performers should also improve their own control ability in daily life. Only the inner peace and not panic state can effectively cope with a variety of unforeseen circumstances occurred in the vocal music performance and increase the contingency ability.

\section{DOING PHYSICAL EXERCISE, ENHANCING THEIR IMMUNITY AND KEEPING A STRONG BODY.}

Vocal music performance is an advanced art mutually combined with a good voice, mental labor and manual labor. A good voice and robust body are every important. If physical health is poor, the immunity will be weak and it's easy to get colds. The cold will cause vocal cord congestion. If the performers carry out the training of vocal music at this time, it will cause severe damage to vocal cord, thus will delay the training of vocal music. Besides, vocal music performance adopts a standing position and still needs the interaction of expressions and movements, especially for some large-scale opera performance, the change for range of motion of the body will be bigger, and this will require excessive physical exertion. During the performance, the legs of many vocal performers start to shake and even their whole bodies are trembling. This is most probably because of physical breakdown, which has a serious effect on vocal music performance and this is also an important reason to cause the psychological tension for vocal performer. Therefore, vocal performers shall pay attention to physical exercise and health at ordinary times. A good physical quality is a material basis for overcoming the psychological tension. The performers shall do aerobic exercises, e.g. jogging, brisk walking and climbing, so as to have a healthy body, avoid the physical breakdown to influence the vocal music performance and relieve the tension of vocal music performance. At the same time, the performers should get plenty of sleep, should not stay up late, abstain from alcohol and tobacco, eat less spicy food, retain a good mood and keep a good voice state. The performer shall carry out scientific training and pay attention to the protection of the throat. If the throat is abnormal, it shall take the corresponding measures immediately. At ordinary times, it shall also be careful for the side effect of the medicine towards throat irritation, especially that girls shall not talk and sing loudly in physiological period, pay attention to the condition in the biological cycle and shall enhance advantage and avoid disadvantage. Keep the throat in the most comfortable condition.

\section{STRENGTHENING THE PRACTICE OF MUSIC ONTOLOGY}

(1) Strengthening the practice of vocalization. Many vocal performers attach little importance on the vocalization and feel that the vocalization has no difficulty and is easier to sing, but it's not. Many vocalizations include the things with a strong technique, including the practice of leap and ligado. 
What's more, the vocalization has played an important role in the control and practice of breath. Only the vocalization is sung skilfully and fluently, can the knowledge mastered from the vocalization be applied to vocal music works skilfully, so as to make vocal music works look more plentiful in the performance.

(2) Strengthening the analysis of vocal music works. After getting a piece of music work, it shall carry out the comprehensive analysis for this piece of vocal music work, including tone mark, beat, rhythm, emotion and meaning expressed in the song. It shall fully understand what kind of artistic conception wants to be expressed in this piece of vocal music work. At the same time, it shall also combine with the vocalization and deliberate the singing repeatedly for several times, so as to improve the understanding level and proficiency for this piece of vocal music work.

\section{MAKING GOOD PREPARATIONS BEFORE SINGING}

(1) If the vocal performer doesn't prepare well enough before singing and lacks of proficiency in the sang tracks; the selection of works is improper, the track is beyond the ability of the performer and the accompaniment is poor; the vocal performer doesn't walk in advance and is unfamiliar with the site and audio. All of these will cause psychological burden, produce psychological tension and make the performers feel feared and distracted. As a result, the performer could not focus all his attention on the vocal music works, and this will cause a great psychological tension.

(2) The heavy burden on the mind and over-high expectation on their own performance. Lack of selfconfidence, not be able to see their own strengths correctly and focus too much on their weakness. Therefore, the performers shall firstly have a good command of singing skills, participate in more performances, enhance the practical ability of stage performance and summarize the experience and lessons from the stage practice. The performers shall select a fair degree of works according to their practical capacity and level; what's more, performance costume shall be fit. The performers shall not distract when wearing unfit clothes. If the dress is baggy, it will be worried about dropping; if the dress is too tight, it will influence the use of breath, therefore, many people wear clothes that don't suit them due to looking good or other reasons and are over-cautious on the stage, so as to cause a strong psychological tension and affect their normal play. The more sufficient the preparatory work is before the vocal music performance, the less likely the psychological tension appears while performing.

\section{DOING MORE RELAXATION EXERCISE BEFORE THE VOCAL MUSIC PERFORMANCE}

Before the vocal music performance, the performers shall relax, take more deep breath and do more exercises of slow inhale and exhale to adjust the breath, so as to relieve the psychological tension before the vocal music performance. At the same time, it can save the physical strength of vocal performer and is conducive to the proper use of breath, especially that the performers shall get down to practising the song to be sung by them over and over again before the performance or examination. We can also avoid the body stiffness incurred by the tension by way of slow walking, which is more conducive to the sinking of breath and increases the sense of relief.

To sum up, the above mentioned are some small tips for overcoming the psychological tension in the vocal music performance. These methods can ease the psychological tension of vocal performers. The vocal performers can adopt those methods to overcome the psychological tension in the vocal music performance according to the practical situation.

\section{REFERENCES}

[1] Luo Xiaoping \& Huang Hong. Psychology of Music. Guangzhou: Sanhuan Publishing House;

[2] Guo Jin. Taking about the Overcome of Psychological Tension in Solo Performance;

[3] Huang Zhong (Journal of Wuhan Conservatory of Music). Supplement;

[4] Yang Yihe. The Principle and Application of Musical Performance Art. Anhui Literature \& Art Press;

[5] Wang Wenling. How to Relieve the Psychological Tension in the Vocal Music Performance. Art Education, 2005 (3);

[6] Liu Feng \& Gong Li. The Analysis and Adjustment for Stage Fright. Small Performer;

[7] Zou Changhai. Artistic Psychology of Vocal Music. People's Music Publishing House;

[8] Shi Weizheng. The Basis of Vocal Music. People's Music Publishing House;

[9] Lazarenko \& Wang Qizhang. Art of Singing. People's Music Publishing House; 